\section{PRAXIS \\ ecucativa}

Universidad Nacional de La Pampa

Facultad de Ciencias Humanas

Instituto de Ciencias de la Educación

para la investigación interdisciplinaria

\section{the \\ Instituto de Ciencias de la Educación
para la Investigación Interdisciplinantl
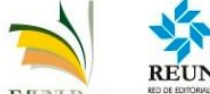 \\ EdUNLPam}

ISSN 2313-934X

SANTA ROSA, LA PAMPA, ARGENTINA

Correo electrónico: iceii@humanas.unlpam.edu.ar

Disponible en https://cerac.unlpam.edu.ar/index.php/praxis

Formación docente y sentidos de frontera. María Graciela Di Franco. Praxis educativa, Vol. 23, No 3; septiembre -diciembre 2019 - E ISSN 2313-9334X. pp. 1-4.

DOI: https://dx.doi.org/10.19137/praxiseducativa-2019-230301

Esta obra se publica baja Licencia CreativeCommons 4.0 Internacional CC BY- NC- SA Atribución, No Comercial, Compartir igual

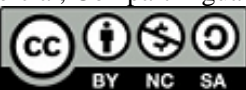

\title{
Formación docente y sentidos de frontera
}

\author{
María Graciela Di Franco \\ Universidad Nacional de La Pampa, Argentina \\ chdifranco\#gmail.com \\ ORCID: 0000-0002-6312-1825
}

Nos hemos concentrado en las editoriales de los volúmenes de este año 2019 en la formación docente, en particular en una formación que pueda acompañar y llevar adelante un proyecto político, el más apropiado para un mundo cada vez más justo, democrático, fraternal, solidario. Nos hemos centrado para ello en analizar la formación a favor de Políticas de redistribución, de reconocimiento y de participación yLa formación de profesores hoy y los desafíos que genera la democracia contemporánea.

Este análisis es importante poder pensarlo en términos locales, de nuestra América, y poder pensar pedagogías rebeldes como dicen Suárez, Hillert, Ouviña y Rigal (2015). Pedagogías rebeldes en un cambio de época y escribiendo desde la lectura de la obra de Gramsci: cómo entender la actividad educadora, académica, particularmente en la formación; y en nuestro caso, en la formación universitaria, entendiendo las prácticas y las experiencias que se puedan llevar adelante en este cambio de época, en este contexto de políticas postneoliberales. En la reflexión de Willis lecturas de Gramsci mediante - señala que si se quieren pensar cambios es necesario otorgar una responsabilidad a la práctica (Willis, 1991, p.461) y recupera, también, el argumento marxista de señalar que la realidad no es un objeto externo de simple contemplación, sino que es una actividad humana, una práctica humana y que la vida social es esencialmente práctica, es en la práctica donde el hombre tiene que demostrar la verdad, es decir, la realidad y el poder, la terrenalidad de su pensamiento (Marx, 1973, p. 9). Entendemos a las pedagogías críticas como pedagogías no complacientes, pedagogías rebeldes, que pueden tomar partido reconociendo a los sujetos sociales 
subalternos, fortaleciendo su autonomia, interesados en la construcción de subjetividades políticas rebeldes y en la producción de saberes, recuperando su memoria histórica, sus discursos y sus prácticas para la resistencia.

Como intelectuales que trabajamos y militamos en el campo de la educación latinoamericana, proponemos una formación centrada en el conflicto, produciendo conocimiento al servicio de la formación de sujetxs protagonistas con potencialidad política y emancipatoria, constructorxs de estrategias políticas y pedagógicas capaces de discutir las herencias recibidas en una educación bancaria.

Pensar de este modo fortalece una formación de profesorxs que apunten al pensamiento y al compromiso crítico con las necesidades de los sectores sociales subalternos; que se valga y valorice el discurso elaborado desde la propia práctica y que lo pueda articular con el pensamiento teóricamente sustentado. Este pensamiento es resignificado dentro de un complejo de saberes y de conocimientos que superan lo educativo, involucran lo social, lo cultural y político y siempre implican saberes en movimiento.

\section{Formación de profesoras/es, sentidos de frontera}

Necesitamos una formación que capacite a lxs docentes actuales y futurxs a tomar partido por un punto de vista crítico respecto a sus situaciones, a la de la escuela, que le permita reducir la ingenuidad política y no entrar en el juego de la restauración conservadora (Apple, 1993). Dice Liston y Zeichner: "la formación del profesorado tiene un importante papel que desempeñar en el movimiento a favor de una sociedad más justa y humana" (1993, p.169). De este modo, la formación no tanto integra a los docentes al orden social actual como trabajar a favor de la reestructuración social. Una formación inicial desde esta perspectiva sentará las bases para el desarrollo profesional docente. Para abordar el análisis de la formación docente, Liston y Zeichner analizan las tradiciones de reforma de la formación del profesorado y describen cuatro: académica, de la eficacia social, desarrollista y reconstruccionista social, siendo esta última la que apunta a una sociedad más justa. Los pedagogos de la frontera afirmaban que el sentido de la educación consistía en:

Preparar a los individuos para tomar parte de forma inteligente en la gestión de las condiciones en las que tuvieran que vivir, llevándoles a comprender las fuerzas que en ellas actúan y equiparlos con las herramientas intelectuales y práctica mediante las que participar en la dirección de estas fuerzas.(Kilpatrik en Liston \& Zeichner, 1933, p. 71)

Ponen énfasis en cultivar la capacidad de pensamiento crítico de los estudiantes respecto al orden social, y de allí la importancia de comprender los problemas sociales, económicos y políticos con los que se enfrentan en el contexto en que viven, capaces de entenderlo, de estudiar en profundidad los problemas sociales y de intervenir en consonancia con ello. Aquí, se vuelve fundamental la construcción de un sentido de la vida que, puesta en acción, dará sentido a todo lo demás, una filosofía de la educación — diría Dewey - que se convierte en objetivo claro de la formación profesional.

No es fácil generar esta mirada hacia una perspectiva social activa y comprometida:

Debe estimularse a todos los profesores a que sepan de primera mano cómo viven y qué sienten los menos favorecidos de entre nosotros. Los contactos de primera mano tienen una fuerza enorme. Nos resulta fácil no tener en cuenta las necesidades de quiénes no conocemos. (...) sin ello no podremos esperar que los profesores adquieran una preparación social. (Kilpatrik en Liston\&Zeichner, 1993, p. 166) 
Estas experiencias de primera mano realizadas en contexto, una formación integrada, un currículum basado en problemas, ayudan a comprender que el trabajo del profesor es de ámbito comunitario. El valor otorgado a la experiencia directa podría favorecer una mirada política de su formación e intervención en el campo profesional.

Giroux (2013) y McLaren (2013) proponen pensar en la formación del profesorado, en cuanto fuerza democrática y antihegemónica, y en los profesores como intelectuales transformadores. Para ello, la formación debe ser pensada como una forma de política cultural basada en el estudio del lenguaje, la historia, la cultura y la política. Es decir, que la orientación social y política consciente de la formación reflexiva sostiene el interés de los pedagogos de la frontera y del reconstruccionismo social.

La base democrática de esta formación podría cumplir — en palabras de Gutmann (1987) — los principios de desarrollar un carácter deliberante y democrático (en lo individual, institucional y social); no puede reprimir la deliberación racional y no puede hacer ningún tipo de discriminación. Para trabajar sobre estos principios, es fundamental reflexionar sobre las creencias sociales que subyacen en la enseñanza, la escolarización y en la formación para situar la acción educativa en un contexto social y político más amplio.

Estos argumentos son sostenidos desde las tradiciones progresista y radical (Liston, 1993) que analizan rol docente, y a la actividad educativa cuestionando con énfasis a la tradición conservadora. El progresismo, en la pluma de Dewey, propone que la formación destine sus esfuerzos en que los estudiantes se conviertan en investigadores competentes, capaces de cuestionar su mundo cotidiano, ayudados por el dominio del contenido de las disciplinas y activar la reconstrucción continua de su experiencia. La tradición radical, en la voz de Freire (2006), Apple (2013) y Giroux (2013), explicita como preocupación central los modos de dar cuenta de las formas de dominación, así como las posibilidades de una acción liberadora.

La reflexión sobre las creencias es fundamental al permitirnos pensar en la formación profesoral y explicitar la coherencia entre lo que decimos, pensamos y hacemos. En general, los programas de formación no analizan estos significados y permanecen implícitos y no articulados con la matriz curricular. Reflexionar sobre las creencias sociales y culturales que subyacen a la enseñanza, aprendizaje, escolarización y sujetos a formar, orientará las modalidades y el sentido de la intervención docente. Para modificar esta matriz curricular es necesario pasar de una formación de asignaturas, de inventario, a una formación con programas alternativos con énfasis en y sobre la práctica. Nuevos sentidos, apuestas y proyecciones de la formación exigen nuestra mirada crítica y decolonial para encaminarnos por una nueva geopolítica del conocimiento, de la teoría, de la práctica (Santos, 2010). Este análisis nos permite discutir la relación teoría y práctica desde la concepción hegemónica binaria, donde ambas se disputan la preeminencia. Proponemos conceptualizar acerca de la praxis decolonial. Esto permitirá un pensamiento posabismal que parta del reconocimiento de la exclusión, que implica una copresencia simultánea contemporánea de los sujetos que se involucran en las prácticas. Una pluralidad de saberes, una ecología de saberes, generando alternativas múltiples (pero no universales ni únicas posibles), que entiendan al conocimiento como intervención en la realidad (Santos, 2010).

Los artículos de este volumen ayudan a pensar esta formación.

Desde el volumen fundacional las y los artistas plásticos de la provincia ilustran los artículos. En este caso las imágenes que acompañan a los artículos son de obras que pertenecen al Patrimonio del Museo Provincial de Artes. 


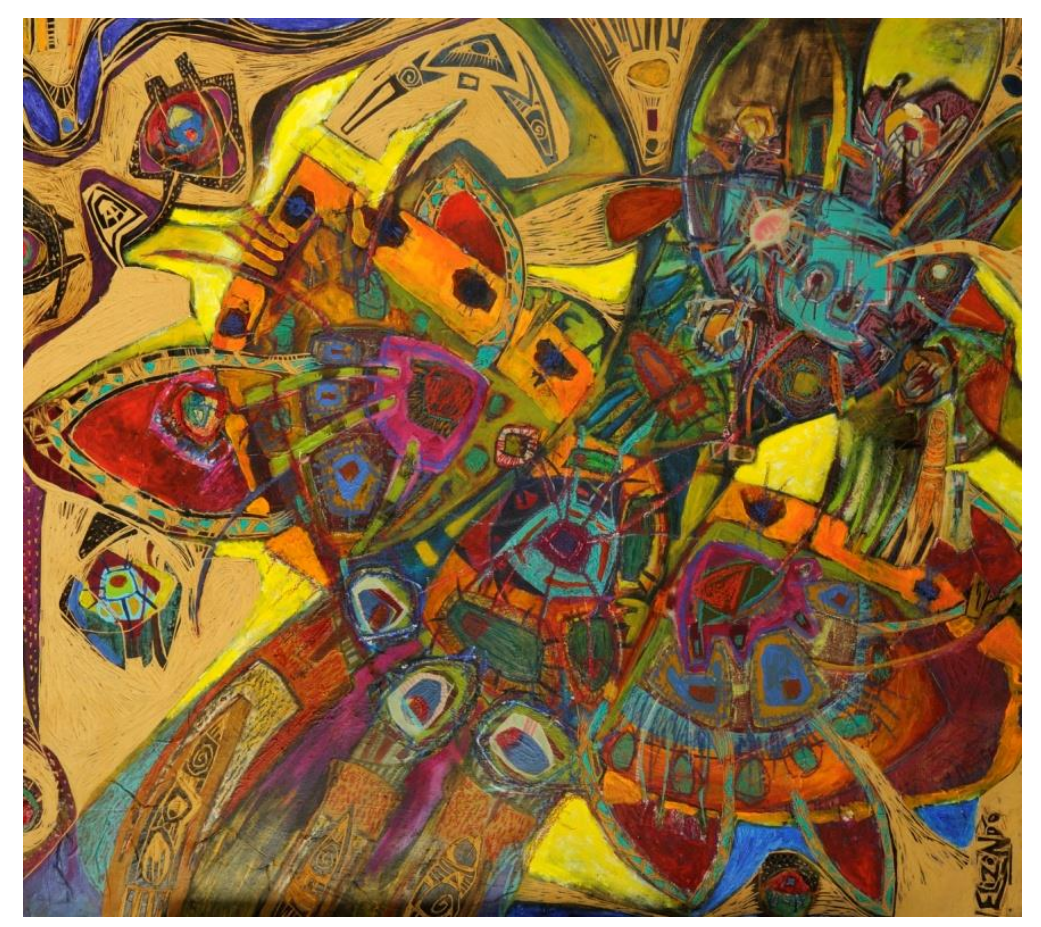

Otro vuelo de la serie bichos y flores, Andrea Elizondo

\section{Bibliografía}

Suarez, D., Hillert, F., Ouviña, H. \&Rigal, L. (2015).Pedagogías críticas en América latina. Experiencias alternativas de educación popular. Buenos Aires, Argentina: Noveduc.

Willis, P. (1991).Aprendiendo a trabajar. Como los chicos de la clase obrera consiguen trabajos de la clase obrera. Madrid, España: Akal.

Liston, D. \&Zeichner, K. (1993). Formación del profesorado y condiciones sociales de la escolarización. Madrid, España: Morata.

Giroux, H. (2013). La pedagogía crítica en tiempos oscuros. EnPraxis educativa, 17(2), 13-26.

Mclaren, P. (2013). La educación como una cuestión de clase. Entrevista a Peter Mc Laren.Praxis educativa, $17(2), 79-90$.

Santos, B.S (2010).Descolonizar el saber, reinventar el poder. Buenos Aires, Argentina: Editorial Trilce. 